\title{
AS ECONOMIAS DO ÍNDICO AQUANDO DA CHEGADA DOS PORTUGUESES *
}

Em carta datada de Goa a 6 de Dezembro de 1515 e dirigida ao rei de Portugal, D. Manuel I, o governador e principal construtor do Império/"Estado português da índia" (1509-1515), Afonso de Albuquerque, fazia, já com os soluços da morte, o último balanço da sua actividade político-militar. E afirmava orgulhoso, mas em parte desgostoso: "deixo a índia com as principaees cabeças tomadas em voso poder, sem nela ficar outra pendença senão cerrar-se e mui bem a porta do Estreito [de Meca ou Mar Vermelho]; isto he o que me vosa alteza encomendou".

Repare-se: a política expansionista, definida pela Coroa/Estado português e executada táctica e estrategicamente por Albuquerque não apenas na índia propriamente dita mas em todo o Oriente (Ásia das monções), teve o mérito, em meu entender, de perceber que as economias e sociedades implantadas no e ao redor do eixo do Índico - Pacífico tinham estabelecido fluxos comerciais multisseculares, acabando esta abertura por conferir-lhes uma certa unidade civilizacional que não apagava (antes pelo contrário) as especifi-

* Texto básico da conferência proferida na Universidade de Poitiers, em Outubro de 1991, integrada no Congresso Mundial sob adesignação"1492-Et le Monde bascula...". 
cidades culturais. Poucas eram, de facto, as culturas que ali se mantinham inteiramente fechadas, concorrendo a presença muçulmana para intensificar, ainda mais, essa comunicação já tradicional.

Deste modo, talvez possamos falar, com propriedade, ao nível mercantil, de uma "economia-mundo asiática", antes da chegada dos portugueses, assente na teia de relações comerciais à distância, mas que não prescindia, obviamente, das pequenas trocas (comércio de cabotagem e transporte por terra, utilizando sobretudo os bovinos). Por sua vez, o grande comércio, cujas principais rotas e portos de escala mais famosos não teremos dificuldade em enumerar, movimentava mercadorias, agentes e meios de pagamento que surpreenderam os ocidentais. Afonso de Albuquerque, por exemplo, dirá que o dinheiro (o ouro e a prata) eram abundantes e que a "índia" era um lago de mercadorias, sendo numerosos os mercadores que vendiam "por grosso" (cf. carta de 20 de Outubro de 1514). Concretamente, os "guzerates" (mercadores do reino de Cambaia) eram solicitados por tratantes de outras nações para constituírem "companhias" comerciais e Tomé Pires (um dos primeiros viajantes portugueses a conhecer mais dilatadamente a "índia") compará-los-á aos italianos na arte de mercadejar ( A Suma Oriental, 1978, p. 198). De facto, a região do Guzerate será o verdadeiro motor das economias do Índico.

Aliás, em paralelismo com o desenvolvimento comercial, verificar-se-á um dilatado e intenso comércio do dinheiro em cidades como Cambaia, Calecute e Goa. Os cambistas ("cambadores" na língua portuguesa de Quinhentos) eram designados "xarafos/sarrafos" e actuavam livremente em "bazares" (grandes armazéns de mercadorias) e nas vias públicas, arrecadando elevados lucros. Na generalidade e relativamente ao fenómeno monetário, o Norte da índia mercantil mostrará preferência pela moeda de prata e cobre (em especial por esta última), enquanto o Sul fará circular também as espécies em ouro. Registe-se, ainda, que as célebres "rupias" de prata só aparecerão no século XVI; que a índia terá de importar o 
metal e/ou as moedas dos "outros"; e que o recurso a pré ou para-moedas, em toda a índia, continuará a ser considerável, o que aponta para o carácter natural de parte da sua economia.

Insistindo, ainda, na caracterização das economias urbanas do Índico, não se esqueça nem o papel dos artífices, nem das pessoas ligadas aos serviços, nem sequer a importância que, pelo menos em algumas, assumem os agricultores. Daremos exemplos de cidades (ou de economias) urbanizadas em que é notório o carácter integrado dos vários sectores, não sendo difícil adivinhar, nestes casos, uma enorme vitalidade, com a correspondente área de influência a alargar-se ou a mundializar-se. Concretamente, em todas elas, o sector dos transportes (dos víveres e até da água, das mercadorias de luxo e das mercadorias vulgares) adquire relevância. Os portugueses, por exemplo, referir-se-ão aos inúmeros "almocreves" que transportavam trigo do Balagate/Decão (zona mais seca) até Goa, onde o vendiam facilmente. E o que se diz do trigo das planícies secas do Indo poderá dizer-se do arroz do baixo Indo ou da pimenta do Malabar transportada em carros de bois também até ao Balagate.

Nos arredores das cidades viviam muitos lavadores de roupa (designados "mainatos") e pelas ruas circulavam intensamente condutores de palanquins e de sombreiros, para maior comodidade dos passageiros.

Sabemos pouco da agricultura antiga da índia, mas o suficiente para falar de culturas ricas como as do trigo, do milho, da cana-do-açúcar e, particularmente, do arroz. Contudo, a divulgação de grandes fomes (a provocarem autênticas hecatombes em mortes naturais e suicídios) é um indicador da forte tradicionalidade das técnicas utilizadas. Mais: o regime político vigente, revelará, nas economias/sociedades não-mercantis e, consequentemente, menos urbanizadas, como a da Índia, o papel das autoridades reconhecidas, no quadro das comunidades aldeãs, sendo enorme a percentagem da produção que tributam aos lavradores/camponeses e aos artífices. Deste modo será possível sustentarem-se determinadas castas com funções religiosas e militares. Os naires do Malabar, 
designadamente, passariam de 150 000, segundo o cômputo de Tomé Pires.

Eis portanto bem vincada, sobretudo à medida que se penetrava no interior da Índia, a presença do regime senhorial, ou seja, um modo de vida aparentemente contrário à actividade mercantil. Será, pois, este um espaço económica e sócio-culturalmente atreito à guerra, o que não significa que não motive e atraia a actividade mercantil. Que o digam, por exemplo, os mercadores de Batecala (e, depois, os vice-reis/governadores portugueses de Goa), quão rico era o comércio dos cavalos árabes e persas que as frequentes guerras suscitavam.

Mas havia outros modos de vida, designadamente para os que habitavam as zonas litorâneas da Índia. Por exemplo, os "naitiás" do Malabar eram grandes ladrões e corsários, negociando também em cavalos e mostrando-se peritos na arte de navegar. Os cronistas portugueses assinalarão a sua presença em Goa, Onor e Baçaim. Igualmente, os "badagas" do Sul da Índia se sustentarão de assaltos e roubos. E, se deixarmos a Índia propriamente dita para observarmos os países das suas margens, diremos que, entre o golfo de Ormuz e o golfo de Guzerate, não havia praticamente cidades. Naitaques/noutaques (da tribo nodhaqui dos baloches) e resbutos/ /resputes (habitando em lugares fortificados) guerreavam os povos do interior e saíam ao mar como corsários, pois eram grandes frecheiros. A rica cidade de Cambaia, no Guzerate, será muitas vezes vítima dos seus ataques ferozes.

Segundo Duarte Barbosa (um português que chegou à Índia na armada de Pedro Álvares Cabral), a "grande e fermosa" cidade de Cambaia estava assentada em terra fértil e os muitos artífices que nela trabalhavam produziam obras diversas e requintadas, como as da Flandres. Designadamente, de fama mundial eram os seus panos de algodão e de seda, os veludos, setins, tafetás, marfins trabalha dos (jogos de xadrez, leitos/camas, cabos de armas...), ourivesaria e pedraria, bordados, roupa de cama... Bons pilotos e "sabidos e mercadoria", conforme já se disse, os guzerates navegavam para 
todo o lado, mas assediavam, com os seus produtos baratos, sobretudo os portos do eixo que se distendia, para oeste, até Adem e, para leste, até Malaca, onde, nomeadamente, adquiriam a seda em bruto de Pacem, Pedir e da China.

A moeda miúda de Cambaia era em cobre, mas moedas de prata (os "mastamudes'7"mahmudis" que chegarão a valer 60 rs e as "madaforxas'7"madrafaxos" do mesmo valor) e barras de ouro serão também elementos de troca dos guzerates. Era, de facto, forte a economia de Cambaia, principalmente devido ao seu carácter integrado, já que à qualidade da sua indústria e ao vigor do seu comércio se associavam a abundância e a elevada produtividade do seu campo: arroz, trigo, cevada, milho, legumes, frutas, gado (cavalos), elefantes e caça diversa.

Em quase toda a Africa Oriental eram conhecidos os panos grossos de algodão de Cambaia, transaccionados pelos guzerates e/ou por mercadores locais, com relevo para os moradores de Adem. Esta cidade será classificada por Tomé Pires como uma das quatro do Mundo com mais trato (A Suma Oriental, p. 145). Situada à entrada do Mar Vermelho, no vértice da "Arábia Feliz" em que a África Oriental e a Ásia quase se beijam, a esterilidade do seu sítio (desértico) não a impediu, contudo, de crescer. Os mantimentos recebia-os através das cidades etíopes de Barbora e Zeila e das ilhas Dalaca, Maçuá e Suaquem. Concretamente, Zeila possuía muito gado (inclusive cavalos para a guerra), leite e manteiga, trigo, milho, cevada e saborosas frutas. Mas, as grandes riquezas da Etiópia/ /Abissínia (a terra do mítico rei-sacerdote cristão Preste João) eram, particularmente, o ouro, os escravos, os cavalos, o marfim e o aljôfar que se pescava no Mar Vermelho. Adem atraía estas mercadorias e completava-as com outras provenientes do Mediterrâneo (recebidas através do Cairo e de Judá - o porto que servia também a cidade santa de Meca) e da Arábia, reenviando-as, depois, para outras cidades-mundo: Ormuz, Cambaia, Calecute, Bengala, Malaca...

Na costa de Fartaque (desde o cabo do mesmo nome, no golfo 
de Adem, até ao cabo de Madraça) vivia gente guerreira, sendo o seu modo de vida andar a soldo "à maneira de Soíços" (carta de el-rei D. Manuel..., de 1508). E, à entrada do Golfo pérsico, perfilava-se Ormuz, acidade-chave para o comércio entre o "mundo persa" e o Índico. Através de Sirafe (um empório) e dos rios Tigre e Eufrates, as mercadorias do Índico tomavam o caminho de Raca e Balis e, depois, seguiam para Alepo e Damasco, encarregando-se as caravanas de as fazerem chegar até aos portos de Berito (Beirute) e Antioquia. Venezianos, genoveses e catalães, entre outros, tinham feitorias nestas cidades, constando o comércio de retorno de: sedas (de Xiria), chamalotes, panos de lã, veludos, brocados, alcatifas e tapetes grandes, chapéus, barretes, almíscar (muito fino), pedras preciosas (entre elas as famosas pérolas das ilhas de Baharem e Julfar), pedra-ume, armas, cavalos (os melhores depois dos árabes), cera, mel, manteiga...

Para a terra do Preste João enviava Ormuz muitos panos persas e para os reinos de Narsinga e do Decão/Daquem alguns milhares de cavalos. Como lastro, as embarcações que carregavam as mercadorias citadas e ainda as frutas secas (tâmaras e passas), o âmbar, o aljôfar grosso, o enxofre, o salitre ou as famosas "tangas" (moedas de prata) levavam pedras de sal-gema que havia em abundância na cidade-chave do Golfo pérsico. À semelhança de Adem, também Ormuz era uma cidade estéril, a ponto de não possuir quase um ramo verde e até a água lhe vir de fora. No entanto, devido ao longo comércio, dispunha de fartura de alimentos, ainda que caros. Duarte Barbosa observará que tudo se vendia em Ormuz a peso, com muito "regimento" e a preços taxados (Livro Em que dá relação..., 1946, pp. 54-58). Como moedas corriam os "xerafins" de ouro (valerão cerca de 300 rs) e as já citadas "tangas" (à volta de $60 \mathrm{rs}$ ). De Adem, mas sobretudo das principais cidades indianas, recebia a importante cidade do Golfo pérsico muito arroz branco, açúcar em pó, especiarias várias (pimenta, canela e gengibre), drogas (que se consumiam "grandemente" na Arábia e na Pérsia), panos, ferro, azougue, vermelhão... De Bengala chegar- 
-lhe-ão panos de algodão muito finos ("sinabasos") para camisas e toucas. Aliás, os habitantes de Ormuz vestiam (e comiam), em geral, muito bem.

Regressemos, porém, à Índia para observar outro porto da "grande navegação" da costa do Guzerate e, portanto, também, com ligações com Adem e Ormuz, já que estas cidades lhe forneciam, nomeadamente, panos de algodão e de seda, gergelim e especiarias. Refiro-me à cidade de Diu.

Com o domínio português, Diu decaiu bastante, afirmando Tomé Pires que o trato habitual acabou por decrescer para a décima parte (Ob. cit., p. 210). Ao invés, no interior do reino de Cambaia, Champanel continuará a afirmar-se, referindo os portugueses que a visitavam que não era grande (sinal do predomínio de uma economia natural), mas que era muito "polida"/civilizada.

Depois do Hidalcão, o Nizamaluco (título genérico dos reis do Daquem/Decão) era o mais poderoso do noroeste da Índia, recorrendo, como se disse, constantemente à guerra para se impor aos "senhores" do seu reino e aos vizinhos. No litoral, prosperavam cidades como Damão, Baçaim, Chaúl e Dabul. A primeira era fértil em mantimentos que exportava e a segunda ganhará fama pela riqueza da sua comarca, em particular pela sua muita e boa madeira, ferro, aço e salitre. Os portugueses ficarão surpreendidos com a vitalidade das aldeias que lhe estavam adjacentes, a ponto de afirmarem que em parte alguma do litoral indiano se encontrava tanta abundância de tudo. Chaúl, além da riqueza do seu campo (com relevo para o arroz, bétele e areca), superintendia no comércio da região, logrando interferir mesmo no tráfego da pimenta que ia para o Mar Vermelho. Dabul era, igualmente, tão rica e populosa como Chaúl.

Com um porto razoável para o embarque, sobretudo, da pimenta e do gengibre (cuja distribuição no Índico assegurava, juntamente com Cochim), Calecute enriqueceu e tornou-se poderosa, estimando os portugueses que seriam 100000 os "homes de peleja" ao serviço do Samorim (título do rei local). Os mercadores 
muçulmanos de Judá, de Meca e do Cairo, com a compra da pimenta, eram quem mais favorecia esta cidade (cf. A Crónica do Descobrimento e Conquista da Índia pelos Portugueses), classificando-a uma gravura do século XVI de "celeberrimum Indiae Emporium" e revelando uma pujante indústria de construção naval (dispunha de muita e rica madeira), além de uma intensa actividade mercantil. Outras fontes afirmam que eram "infindos" ali os mercadores e Tomé Pires dirá que se faziam, na cidade, naus de quilha, de 1000 e 1200 "bahares" (4 000 e 4800 quintais) de carga, que transportavam os cerca de 80000 quintais de pimenta produzida no Malabar, os 2000 quintais de gengibre, areca (exportada, sobretudo, para Cambaia), óleo de coco, tamarindo, cairo ou esparto (fio para calabres e cordoalha). Além disso, era quase suficiente em produtos alimentares, podendo contar, para isso, com o reino de Narsinga, de onde lhe vinha também a preciosa pedraria.

Cananor, Tanor, Panane, Cranganor, Coulão e Comorim eram outros portos importantes do Malabar, estimando-se em quatro centenas só as embarcações de fundo chato que passavam pelo pouco profundo estreito de Ceilão e provinham daquela região. Mas, todas estas cidades eram subsidiárias de Calecute, porque enriqueciam à sua sombra (com o comércio da pimenta) e alimentavam-na quando necessário (caso do arroz de Cananor). Partia-se, daqui, para Judá, no Mar Vermelho, em Fevereiro, com os favores da "monção" e regressava-se entre meados de Agosto e meados de Outubro do ano seguinte, podendo enriquecer-se só numa destas viagens (cf. Duarte Barbosa, Ob. cit., p. 91).

Propositadamente, deixámos para o fim a referência à cidade de Goa, por ter sido dos espaços que mais foram afectados com a presença portuguesa na Índia. O facto de ter pertencido ao reino do Decão e se ter emancipado politicamente denuncia as suas enormes capacidades agrícolas, comerciais e até industriais. Pelo seu "muito bom" porto saíam, concretamente, o famoso bétele, os "beirames", "beatilhas" e outros panos, enquanto cáfilas dos reinos de Narsinga e do Decão lhe asseguravam outros contactos por terra. Os es- 
taleiros de Goa adquiriram fama e diferentes oficiais mecânicos grangeavam-lhe mais riquezas, enquanto mercadores e terratenentes eram outras categorias sócio-profissionais importantes da cidade que foi capital do Império/Estado da Índia Portuguesa.

Abaixo de Quistna e Tungabadrá, ou seja, na parte meridional da Índia, era o reino de Narsinga/Bisnaga onde o rei, à excepção da costa do Malabar, dominava, incluindo o litoral do Coromandel. Lá para o interior, quer Bisnaga, quer Rachol afirmavam-se como cidades robustamente fortificadas e com numerosos efectivos militares, louvando os portugueses a fertilidade dos seus campos (com arroz, trigo, milho e grãos) e a riqueza armazenada. Bisnaga, em particular, dispunha de imensa pedraria (rubis, diamantes, esmeraldas e pérolas), bons panos e outras obras artesanais. Do campo mais próximo afluíam diariamente aos seus mercados cerca de 2000 carros de bois com vegetais, pescado e animais vivos, tudo a preços muito baratos. Por sua vez, o porto de Batecala assegurava, na costa do Malabar, as relações com o exterior (cf. Chronica dos Reis de Bisnaga...).

A Crónica do Descobrimento e Conquista da índia pelos Portugueses registará que o reino de Narsinga chegou a dispor de 100000 homens de cavalo, 1000 elefantes de guerra e "infinita" gente de pé. Este imenso aparelho militar visava sustentar um regime senhorial extremamente retesado (com relações de interdependência pessoal fortes e uma taxa de tributação que podia atingir 9/10 da produção). Daí que, todos os anos, o reino de Bisnaga comprasse cerca de 3000 cavalos a Ormuz e a Adem e que importasse um bom número de elefantes do Ceilão. Por sua vez, a imensa riqueza em ouro e pedraria possibilitava a aquisição daquelas mercadorias, permitia a oferta de valiosos "dons"/dádivas no quadro do regime senhorial, viabilizava enfim o esplendor dos potentados militares Além disso, realizava algumas exportações, não apenas através de Batecala, mas também de Calecute. Registe-se a propósito que os portugueses enviarão mensageiros a comprar jóias ao reino de Narsinga. 
A norte do rio Liga, localizava-se o reino do Hidalcão, sujeito a um regime senhorial semelhante ao de Narsinga (ambos os potentados se guerreavam), enquanto do reino de Orixá/Orissa/Otissa (a sul de Godavari) quase só nos chega a fama das suas "roupas".

A ilha de Ceilão, além dos seus elefantes e das suas pérolas, dispunha de excelente canela, a qual exportava para Adem (com destino ao Mar Vermelho e ao Meditterâneo) e para Malaca. Uma das rotas desta especiaria e da pimenta do Malabar sulcará o "canal das Maldivas".

Antes do descobrimento do "canal" de Malaca, em começos do século XV, os guzerates comerciavam directamente com Java (pela banda do sul) e entravam entre Sunda e a ponta de Samatra até Agraci, donde traziam produtos valiosos (designadamente o ouro) de Timor, Celebes, Bornéu, Molucas, Banda e China (A Suma Oriental, pp. 202-203).

Com a riqueza que o comércio lhe foi proporcionando, Malaca, estimulada certamente pela presença de muçulmanos, logrou cortar os laços que politicamente a uniam ao rei de Sião e converter-se numa espécie de Veneza do Oriente, procurada por mercadores de todas as regiões, em particular os guzerates.

Em sítio abrigado das monções gerais (no que levava vantagem a Singapura), bastava aos navegantes/mercadores aproveitarem as marés e os "terrenhos" para singrarem entre a península malaquesa e Samatra e entrarem na palúdica w insalubre Malaca. Com os "nortes" e "nordestes" (de Novembro a Abril) desgarravam e chegavam as embarcações da China, do Camboja, do Sião e do Pegu, podendo os mesmos ventos permitir o retorno das que haviam partido da Índia; entre Maio e Agosto, com os ventos "sul" e "sueste", movimentavam-se os navios provenientes de Timor, Molucas, Celebes, Bornéu e Java. Como se vê, os regimes dos ventos do Índico e do Pacífico concorriam para o encontro, ali, na península malaquesa, das respectivas navegações.

Malaca era, de facto, uma cidade preferencialmente aberta para 
o mar, quase se esquecendo da terra (como o evidenciava a organização do respectivo espaço urbanizado), já que até a maior parte do que consumia lhe vinha de fora, designadamente de Bengala, do Sião, do Pegu e da costa do Coromandel, em troca, por exemplo, da pimenta de Pedir e de Samatra.

Efectivamente, Bengala era terra abastada de arroz, legumes, açúcar, conservas (em açúcar e vinagre), gado vacum, panos de algodão e de seda, ferro e escravos, embora a maior parte da população morresse de fome e frio. Os preços eram muito baratos, a ponto de, nos começos do século XVI, se comprarem 10 "fardos" (30 alqueires) de arroz por um "pardau"(320 rs); 20 galinhas por uma "tanga" (60 rs); 3 vacas por um "pardau"; e 1 escravo por 6 "tangas". O ouro, o cobre e os corais corriam como moedas e pré-moedas (cf. Lembramça d'algumas cousas que se passaram quando António de Brito e Diogo Pereira foram a Bengala...). Partia-se de Bengala em começos de Fevereiro e chegava-se a Malaca mais de um mês depois, sendo o regresso, de acordo com a monção, na entrada de Setembro.

Também o Pegu era uma das terras mais fartas (Tomé Pires, ob. cit., p. 229). Da cidade do Pegu ia-se ao porto de Dugum/Dogou em um dia, podendo observar-se ali embarcações de Cambaia ou juncos. A 50 léguas de Dugum estava o porto de Cosmin (o principal do reino do Pegu) e, entre outras, era fácil ver "naus" de Adem e Cambaia com roupa e anfião para trocar por alacre e beijoim do Jangomá (na fronteira com o Sião) ou por almíscar do Homucão/ /Mucão ou por rubis do Avá (nas proximidades da China). Mas, estes eram já outros "mundos", em parte alheios ao Índico.

JOÃO MARINHO DOS SANTOS

\section{FONTES UTILIZADAS}

ALBUQUERQUE, Afonso de - Cartas (e outra documentação vária como epistolar e normativa...) in Alguns Documentos de Archivo Nacional da Torre do 
Tombo ácerca das navegações e conquistas portuguesas, Lisboa, Imprensa Nacional, 1892.

ANÓNIMO - Livro das Cidades, E Fortalezas, Que A Coroa de Portugal Tem Nas Partes Da Índia, E Das Capitanias, E Mais Cargos, Que Nelas Há, E Da Importancia Delles [1582?], in "Boletim da Biblioteca da Universidade de Coimbra", vol. XXI, Coimbra, 1953.

ANÓNIMO - Chronica dos Reis de Bisnaga, manuscripto inedito do seculo XVI, publicado por David Lopes, Lisboa, Imprensa Nacional, 1897.

ANÓNIMO - Roteiro da viagem de Dom Vasco da Gama à Índia, por Diogo Kopkee António da Costa Paiva, Porto, Na Typ. Comercial Portuense, 1838. ANÓNIMO - Crónica do Descobrimento e Conquista da Índia pelos Portugueses, leitura de Adélia Lobato e introdução e notas de Luís de Albuquerque, Coimbra, Junta de Investigações do Ultramar, 1974.

BARBOSA, Duarte - Livro Em que dá relação do que viu e ouviu no Oriente Duarte Barbosa, Lisboa, Agência Geral das Colónias, 1946.

BRITO, António de e Diogo Pereira - Lembrança d'algumas cousas que se passaram quando António de Brito e Diogo Pereira foram a Bengala... in Voyage dans les Deltas du Gange et de l'Irraouadi 1521, Paris, Fondation Calouste Gulbenkian, 1988, presenté et edité par Genevieve Bouchon et Luis Filipe Thomaz.

CASTRO, D. João de - Primeiro Roteiro da Costa da Índia, desde Goa até Dio: Narrando a viagem quefez o Vice-Rei D. Garcia de Noronha em socorro desta última cidade (1538-1539), Porto, Typ. Comercial Portuense, 1843.

DOCUMENTAÇÃO para a História das Missões do Padroado Português do Oriente, Lisboa, Agência Geral do Ultramar.

GALVÃO, António - Tratado dos Descobrimentos Antigos e Modernos, Feitos até a Era de 1550, com os nomes particulares das pessoas que os fizerão [...], Lisboa Occidental, Na off. Ferreiriana, 1731.

PIRES, Tomé -A Suma Oriental de Tomé Pires e o Livro de Francisco Rodrigues, leitura e notas de Armando Cortesão, Coimbra, por Ordem da Universidade, 1978. 